\title{
Description of three new species of the genus Allochthonius Chamberlin, 1929 (Pseudoscorpiones: Pseudotyrannochthoniidae) from China
}

\author{
Junfang Hu ${ }^{1}$ \& Feng Zhang ${ }^{2}$ \\ ${ }^{1,2}$ College of Life Sciences, Hebei University, Baoding, Hebei 071002, China \\ Email: ${ }^{1}$ jfanghu@gmail.com, ${ }^{2}$ dudu06042001@163.com (corresponding author)
}

Date of publication (online): 26 November 2011 Date of publication (print): 26 November 2011 ISSN 0974-7907 (online) | 0974-7893 (print)

Editor: Mark S. Harvey

\section{Manuscript details:}

Ms \# 02767

Received 19 April 2011

Final received 10 September 2011

Finally accepted 18 October 2011

Citation: Hu, J. \& F. Zhang (2011). Description of three new species of the genus Allochthonius Chamberlin, 1929 (Pseudoscorpiones: Pseudotyrannochthoniidae) from China. Journal of Threatened Taxa 3(11): 2167-2176.

Copyright: ( ) Junfang Hu \& Feng Zhang 2011. Creative Commons Attribution 3.0 Unported License. JoTT allows unrestricted use of this article in any medium for non-profit purposes, reproduction and distribution by providing adequate credit to the authors and the source of publication.

Author Details: see end of this article

Author Contribution: JH undertook illustration identification and wrote the manuscript. FZ supervised Junfang $\mathrm{Hu}$ during the study and provided necessary suggestions during manuscript preparation.

Acknowledgements: This text benefited greatly from helpful comments by Dr. Volke Mahnert (Muséum d'Histoire Naturelle, Geneva), and many thanks are expressed to Dr. Mark Harvey (Western Australian Museum, Perth, Australia) for supplying data for inclusion in the map. Thanks are also given to Dr. Hirosh Sakayori (Mitsukaido Daini Senior High School) and Dr. Hidebumi Sato (Tsurumi Girls' Senior High School) for kindly donating valuable literature. This work was supported by the National Natural Science Foundation of China (No. 31071885, 30970325, 31093430).

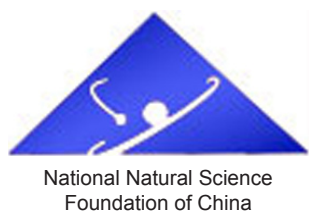

OPEN ACCESS | FREE DOWNLOAD
Abstract: The pseudoscorpion genus Allochthonius Chamberlin, 1929, belonging to the family Pseudotyrannochthoniidae Beier, 1932, is reported from China, and the subgeneric characters of Allochthonius (Allochthonius) are reviewed in detail. Three new species are diagnosed, described and illustrated under the names Allochthonius (A.) fuscus sp. nov., $A$. (A.) wui sp. nov. and $A$. (A.) trigonus sp. nov. A distribution map and a key to the species of subgenus Allochthonius (A.) are provided. In addition, Centrochthonius sichuanensis Schawaller, 1995 is transferred to Allochthonius, forming the new combination $A$. (A.) sichuanensis (Schawaller).

Keywords: Allochthonius, Centrochthonius, China, new species, pseudoscorpions, taxonomy, transfer.

\section{INTRODUCTION}

The pseudoscorpion genus Allochthonius was erected by Chamberlin (1929) for the Japanese type species Chthonius opticus Ellingsen, 1907. This genus was later divided into three subgenera, Allochthonius, Urochthonius Morikawa, 1954 and Spelaeochthonius Morikawa, 1954, by Morikawa (1960) based on the presence or absence of eyes, carapacal chaetotaxy and characteristics of the cheliceral fixed finger teeth. Muchmore (1967) used the morphology of the coxal spines and carapacal chaetotaxy to transfer Allochthonius (Spelaeochthonius) to Pseudotyrannochthonius Beier, 1930. Harvey (1991, 2009) agreed with this view which is reflected in the catalogue of the Pseudoscorpiones, and which we follow in this paper. Presently, the genus Allochthonius is composed of two subgenera Allochthonius and Urochthonius, which are widely distributed in Japan and South Korea. The subgenus Allochthonius (Allochthonius) is composed of seven species, and Allochthonius (Urochthonius) includes eight species (Harvey 2009).

While examining pseudoscorpion specimens collected by Dr. Min Wu and Prof. Fusheng Huang from southern and western China, we found some Allochthonius specimens belonging to the subgenus Allochthonius (Allochthonius). Three new species are recognized, which are described and illustrated in this paper. In addition, we assess the taxonomic position of Centrochthonius sichuanensis Schawaller, 1995 which has many characteristics of Allochthonius. 


\section{MATERIALS AND METHODS}

The patterns of description and the terminology follow Chamberlin (1931) and Harvey (1992). This setal formula of the palpal femur mainly follows Vachon (1941), but the difference from his method is that we divided the "ventral" to "posteroventral" and "anteroventral" (rows in sequence anterioranterodorsal-dorsal-posterodorsal-posterior-posteroventral-anteroventral). The term "rallum" (for flagellum) is adopted following Judson (2007). All specimens are preserved in $75 \%$ alcohol and were examined and illustrated under a Leica M165c stereomicroscope with a drawing tube, which was also used for the measurements. Detailed examination was carried out with a Nikon YS100 general optical microscope. Temporary slide mounts were made in glycerol. All measurements are given in $\mathrm{mm}$. The specimens referred here are deposited in the Museum of Hebei University (MHBU), Baoding City, China.

The following abbreviations are used in the text for the trichobothria: $\mathrm{b}$ - basal; sb - sub-basal; st - subterminal; $\mathrm{t}$ - terminal; ib - interior basal; isb - interior sub-basal; ist - interior sub-terminal; it - interior terminal; eb - exterior basal; esb - exterior sub-basal; est - exterior sub-terminal; et - exterior terminal; $d x$ -trichobothria dx. 6-4, 18 refer to carapacal chaetotaxy: carapace with 18 setae, anterior margin with six setae and posterior margin with four setae.

\section{RESULTS}

\section{Allochthonius (Allochthonius) Chamberlin, 1929}

Morikawa, 1960: 98; Harvey, 1991: 132.

Description: Carapacal chaetotaxy: $6-4,18 ; 8-4$, $22 ; 8-4,24 ; 10-4,24 ; 10-4,26 ; 10-4,28$; or $10-4$, 30. Four eyes, anterior eyes with developed tapeta and situated on eye-tubercles, posterior eyes with less developed tapeta than anterior ones and without eyetubercles. Epistome and spinneret are generally absent but sometimes present. Cheliceral palm with five or six setae, fixed finger generally provided with one large basal and one subapical teeth, and between them two or three small teeth (or with only one basal large tooth and a few small teeth before it, or with several small teeth on the median swelling without any large tooth).
Rallum composed of a biseriate row of about eight to eleven pinnate setae. Chelal finger with well-spaced and prominent marginal teeth, and movable finger with a tubercle between two teeth (Figs. 6, 13, 21, 26). Coxal spines present on coxae I only, consisting of a tubercle expanded terminally into a spray of about four to ten clavate, fan-shaped or gladiate spines. With a well developed bisetose intercoxal tubercle. Palps, chelicerae and legs relatively short and robust.

Distribution: China, Japan, South Korea.

Remarks: Allochthonius (Allochthonius) is similar to the subgenus Allochthonius (Urochthonius) in that: the chelal fingers have well-spaced and prominent marginal teeth; coxal spines are only present on coxae I, consisting of a tubercle expanded terminally into a spray of about eight processes, which extend anteriorly and more or less shield the apical process of coxae I (Morikawa 1960). The two subgenera A. (Allochthonius) and A. (Urochthonius) can be distinguished by the presence of four eyes, or blind or rarely with two eyes, respectively, which is consistent with Morikawa's (1960) viewpoint, but the differences from his system is by the dental morphology and tooth number on the cheliceral fixed finger and the number of setae on the cheliceral palm. For instance, Allochthonius (A.) montanus and Allochthonius (A.) shintoisticus both have four eyes, but the cheliceral fixed finger has one large and a few small teeth and five setae on the cheliceral palm in the former, and the cheliceral palm with five setae in the latter.

In addition, while examining the specimens collected from China, we found a significant characteristic in all species: the palpal movable finger has a tubercle between two teeth. This tubercle is present in Allochthonius (A.) tamurai (cf. Sakayori, 2003: 25, fig. 5a; 27, fig. 21a), but Sakayori (2003) did not refer to this tubercle in the description. We infer that this characteristic might only exist in the subgenus Allochthonius (Allochthonius), so further study to all species of Allochthonius, with especial attention to the movable chelal fingers, is required.

Composition: The subgenus Allochthonius (Allochthonius) comprises seven species (including two subspecies), and distributed in East Asia (Fig. 27); five species distributed in Japan (Allochthonius (A.) borealis Sato, 1984, Allochthonius (A.) montanus Sakayori, 2000, Allochthonius (A.) shintoisticus Chamberlin, 1929, Allochthonius (A.) tamurai 
Sakayori, 1999, Allochthonius (A.) opticus (Ellingsen, 1907) (with the subspecies Allochthonius (A.) opticus opticus (Ellingsen, 1907), Allochthonius (A.) opticus troglophilus Morikawa, 1956); two species, Allochthonius (A.) buanensis W.K. Lee, 1982 and Allochthonius (A.) coreanus Morikawa, 1970, are in South Korea. The three new species described here also belong to this subgenus (Allochthonius $(A$.) trigonus sp. nov., Allochthonius (A.)fuscus sp. nov. and Allochthonius (A.) wui sp. nov.). In addition, we also include Allochthonius (A.) sichuanensis (Schawaller, 1995) from China in this subgenus.

\section{Allochthonius (Allochthonius) sichuanensis (Schawaller, 1995), comb. nov.}

Centrochthonius sichuanensis Schawaller, 1995: 1046-1048, Figs. 1-5.

\section{Remarks: Centrochthonius sichuanensis} Schawaller, 1995 was described from material collected in Wolong Nature Reserve, Sichuan Province, China. The description indicates that the epistome is absent, the coxal spines are on a tubercle, and the carapace has a high number of setae. All of these characters conform to the diagnosis of Allochthonius, not Centrochthonius (M.S. Harvey, pers. comm.). The presence of eyes suggests that it can be treated in the subgenus Allochthonius. We therefore transfer this species to Allochthonius (Allochthonius), and form a new combination, Allochthonius (A.) sichuanensis (Schawaller, 1995).

\section{Allochthonius (Allochthonius) fuscus sp. nov.} (Figs. 1-8)

Type material: Holotypemale, 24.iii.1975,26004'N \& 119 $21^{\prime}$ 'E, Fuzhou City, Fujian Province, China, (Ps.MHBU-FJ750324), Fusheng Huang leg.; Paratypes: 03.iii.1983, one male (Ps.-MHBU-FJ750325), two females (Ps.-MHBU-FJ750326-750327), $30^{\circ} 13^{\prime} \mathrm{N}$ \& 12006'E, alt. 134m; Hangzhou City, Zhejiang Province, China, Fusheng Huang leg.

Diagnosis: Chelal palm obviously dark in color; carapacal chaetotaxy (Fig. 1) 8-4-4-2-4 (22); coxal spines present on coxae I and consisting of 10 tridentate blades, each blade with a central spine terminally distinctly expanded as fan-shaped, all situated on a common tubercle (Fig. 4). This new species is closely related to Allochthonius (A.) tamurai from Japan, but can be distinguished from the latter by the number of coxal spines (six blades spines in latter) and by the shape of the coxal spines (gladiate in latter).

Etymology: The specific name is derived from the Latin word "fuscus" means dark colored, referring to the color of the chelal palm.

Description: Relatively large species. Body (Image 1) yellow, chelal palm strong yellow and other segments of chela pale yellow. Carapace subquadrate and slightly shorter than broad (0.9 times), carapace indistinctly constricted posteriorly; anterior eyes with well developed tapeta and situated on tubercles, posterior eyes less developed tapeta than anterior ones and without eye-tubercles; epistome absent, space between median setae straight or slightly recurved; chaetotaxy 8-4-4-2-4 (22).

Tergal chaetotaxy 4: 4-7: 6-9: 7-9: 7-10: 8-11: 10-11: 10-12: 8-10: 7-10: 2-4 (two tactile setae): 0 . Male anterior genital operculum with eight setae, genital opening pit-like in the basal half, 11 marginal

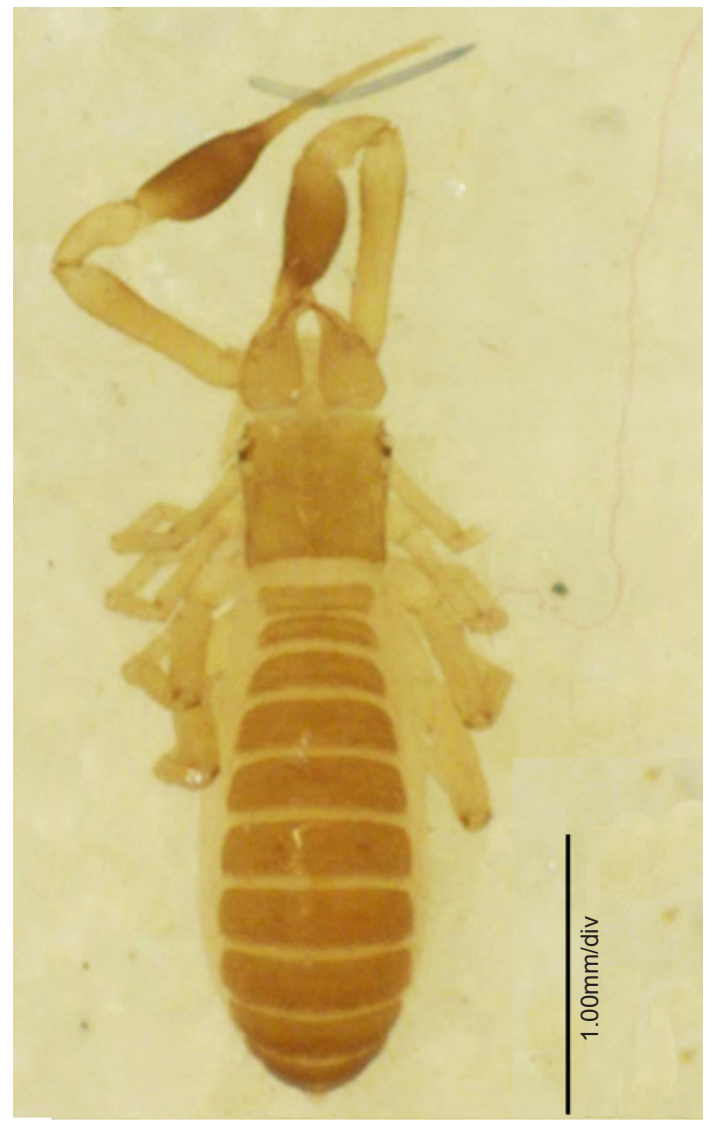

Images 1. Habitus, Allochthonius (Allochthonius) fuscus sp. nov 

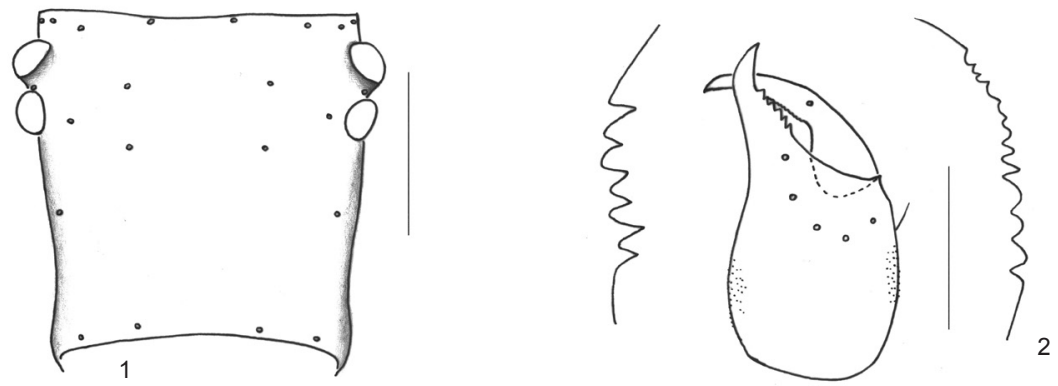
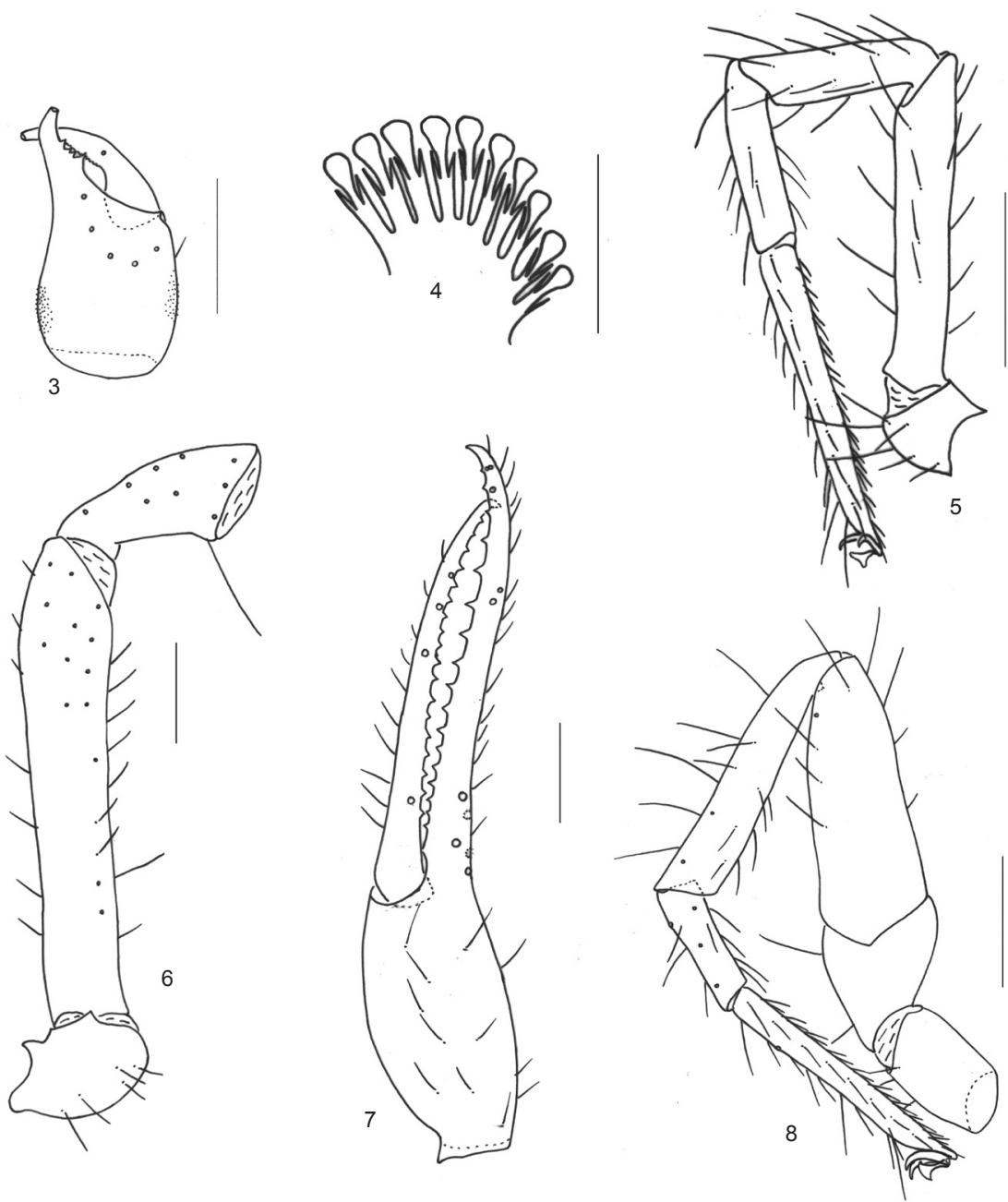

Figures 1-8. Allochthonius (Allochthonius) fuscus sp. nov. 1 - carapace, dorsal view; 2 - right chelicera, dorsal view; 3 - paratype male fixed and movable fingers on right chelicera, dorsal view; 4 - coxal spines; 5 - left chelal trochanter, femur and patella, dorsal view; 6 - left chela, lateral view; 7 - leg I; 8 - leg IV. Scale lines: $0.25 \mathrm{~mm}(1-3$, 5-8), 0.05mm (4). setae on each side; sternal chaetotaxy: $12-13+2 \times 2-3$ suprastigmatic microsetae: $12-13+2 \times 2-3: 15: 15$ : 12: 13: 12: 9: 0: 2. Coxae typical, setae P 5, I 4, II 5, III 7, IV 7; intercoxal tubercle present with two setae. Coxae I each with ten spines, arranged on a common tubercle.

Cheliceral palm with six setae, of which a minute one is located laterally; palm with moderate hispid granulation interiorly and laterally. Fixed finger of holotype (Fig. 2) with six teeth, of which nearly equal length (paratype (Fig. 3) with one large basal and one subapical teeth, between them with two small teeth); movable finger with 14 relatively small teeth of equal length; spinneret absent. Serrula exterior with 17 lamellae, serrula interior with 13 lamellae. Rallum composed of 11 blades with fine barbules, of which the posterior blade is shorter than others.

Palp smooth, femur 2.0 times longer than carapace, setal formula 7-9-4-3-5-5-2; chelal palm distinctly expanded towards internal side, chelal finger straight in dorsal view; fixed finger with 17 teeth, first three and last four teeth smaller than others; movable finger with 
18 teeth, all of which nearly equal length and smaller than fixed finger teeth, and with a tubercle between the ninth and tenth teeth from distal end (Fig. 6).

Legs (Figs. 7, 8) typical. Femur of leg I 2.2 times longer than patella, tarsus 2.0 times longer than tibia, setae of leg I (trochanter to tibia) 6: 15: 12: 10, setae of leg IV (trochanter to metatarsus) 3:2: 9: 15: 12; patellae of legs III and IV each with four setae in dorsal row; femur III and IV without dorsal setae; trochanter II with four setae, trochanter III with two setae. Leg IV with two tactile setae present on metatarsus (TS= 0.27 ) and tarsus (TS $=0.23)$.

Measurements (ratios in parentheses; for the palp, the larger measurements and lower ratios only referring to male). Body length 2.25. Carapace $0.49 \times 0.54(0.9)$. Chelicera $0.52 \times 0.26(2.0)$, movable finger length 0.30 . Palp femur $1.05-1.22 \times 0.20-0.22$ (5.3-5.5), patella $0.50-0.55 \times 0.21-0.23 \quad(2.3-2.4)$, chela $1.47-1.80 \times 0.30-0.36$ (4.9-5.0), palm length 0.52-0.69 (1.7-1.9), movable finger length 0.94 $1.02(1.5-1.8 \times$ palm $)$. Leg I femur $0.47 \times 0.08(5.9)$, patella $0.29 \times 0.07$ (4.1), tibia $0.28 \times 0.06(4.7)$, tarsus $0.46 \times 0.05$ (9.2); leg IV femur+patella $0.75 \times 0.23$ (3.3), tibia $0.57 \times 0.10$ (5.7), metatarsus $0.26 \times 0.08$ (3.3), tarsus $0.52 \times 0.05(10.4)$.

Distribution: China (Fujian, Zhejiang).

\section{Allochthonius (Allochthonius) wui sp. nov.}

(Figs. 9-16)

Type material: Holotype male, 07.vi.1997, $36^{0} 50^{\prime} \mathrm{N} \& 101^{0} 59^{\prime} \mathrm{E}$, alt. 2699m, Huzhu National
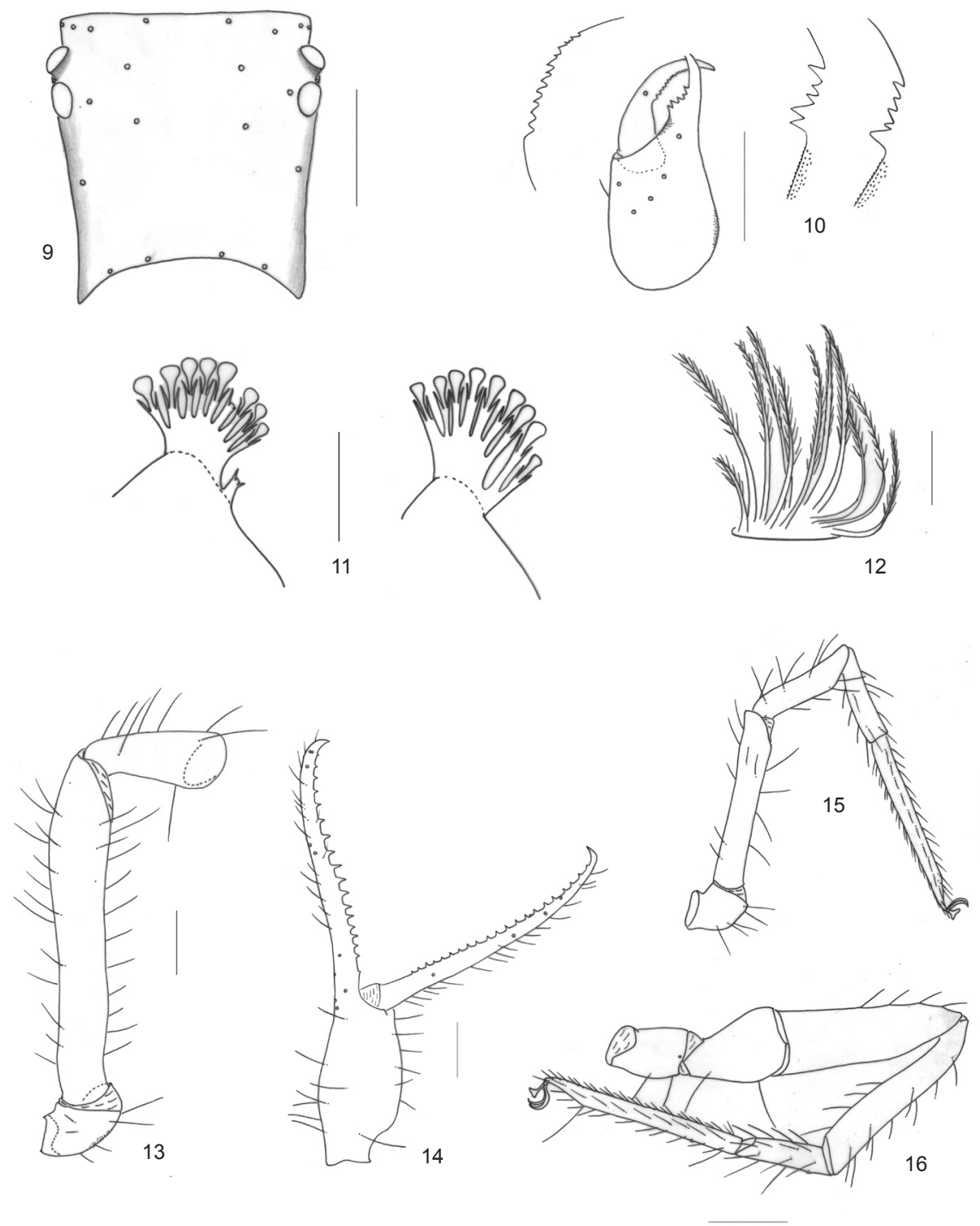

Figures 9-16. Allochthonius (Allochthonius) wui sp. nov. 9 - carapace, dorsal view; 10 - left chelicera, dorsal view; 11 - coxal spines; 12 - rallum; 13 - right chelal trochanter, femur and patella, ventral view; 14 - right chela, lateral view; 15 - leg I; 16 - leg IV. Scale lines: $0.25 \mathrm{~mm}(9,10,13-16)$, $0.05 \mathrm{~mm}(11-12)$. 


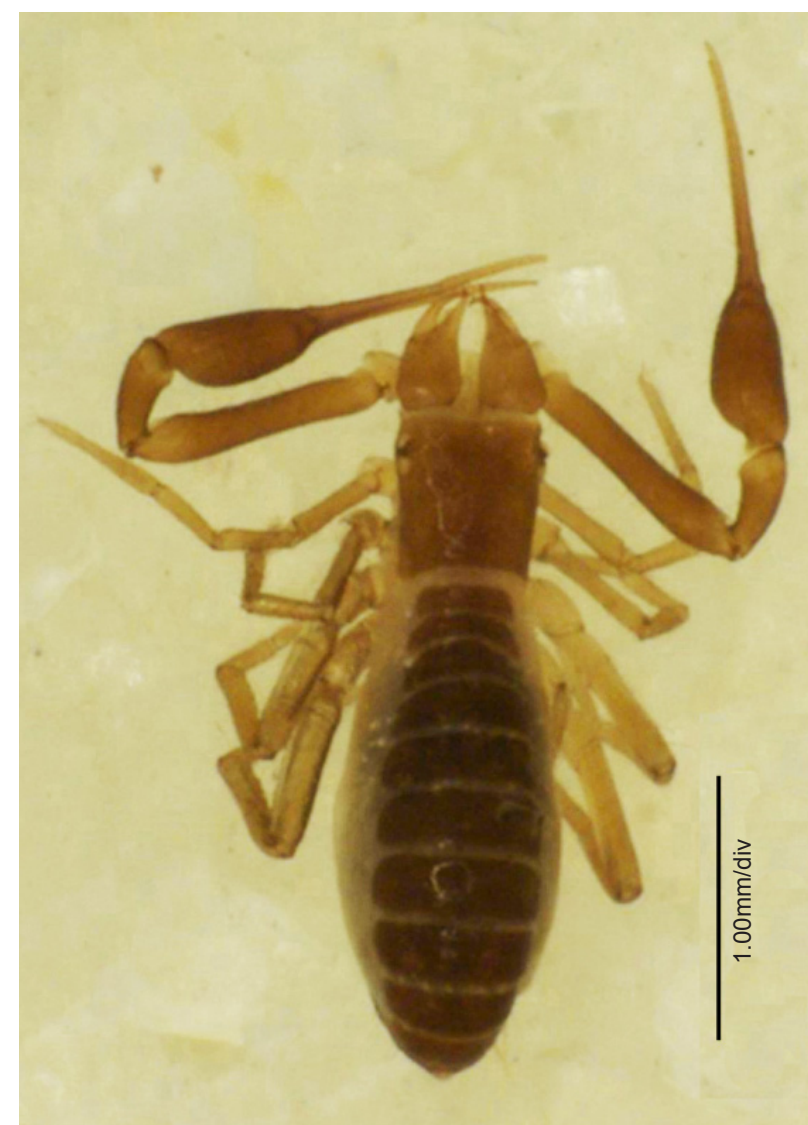

Images 2. Habitus, Allochthonius (Allochthonius) wui sp. nov.

Forest Park, Qinghai Province, China, (Ps.-MHBUQH970607), Min Wu leg.; Paratypes: 08.vi.1997, one male (Ps.-MHBU-QH970608), 12 deutonymphs (Ps.-MHBU-QH970609-970620), 36050'N \& 10159' E, alt. 2699m, Huzhu National Forest Park, Qinghai Province, China, Min Wu leg.

Diagnosis: Large species and body with dark color (Image 2); coxal spines present on coxae I and consisting of ten tridentate blades, each spine with the central one terminal distinctly fan-shaped (Fig. 11). This species resembles Allochthonius (A.) shintoisticus Chamberlin, 1929 from Japan, but differs from it by the chaetotaxy of the carapace (22 setae in A. wui and 24 in A. shintoisticus), by the cheliceral palm (six setae in $A$. wui and five in A. shintoisticus), and by the shape of coxal spines (fan-shaped in $A$. wui and clavate in $A$. shintoisticus).

Etymology: The specific name is named after Prof. $\mathrm{Min} \mathrm{Wu}$, who collected the specimens.

Description: Body deep brown, and chelicerae dark yellow. Carapace subquadrate ( 0.9 times), basally constricted, chaetotaxy 8-4-4-2-4, 22; epistome absent; anterior eyes with well developed tapeta and situated on eye-tubercles, posterior eyes with less developed tapeta than anterior ones and without eyetubercles.

Tergal chaetotaxy 4: 5-6: 6: 7: 9: 10:10-11:1011: 8: 6: TT: 0 . Male anterior genital operculum with eight setae, genital opening pit-like in the basal half, 12 marginal setae on each side; sternal chaetotaxy: 12 $+2 \times 3$ suprastigmatic microsetae: $12+2 \times 3: 13: 12$ : 13: 13: 12: 8: 0: 2. Coxae typical, setae P 5, I 4, II 5, III 6, IV 6; intercoxal tubercle present with two setae. Holotype male coxae I each with 10 tridentate spines (paratype male with nine spines), nine blades arranged on a common tubercle, one blade aside.

Cheliceral palm with six setae, of which a minute one is located laterally; palm nearly smooth, but near the base of fixed finger and interior side with distinctly acute granules (Fig. 10); right fixed finger with one large basal and subapical tooth and between them with three small teeth, but the left finger with two large basal teeth and one large subapical tooth, between them two small teeth; movable finger with 13 small teeth of equal length; spinneret absent, serrula exterior with 19 lamellae, serrula interior with 16 lamellae. Rallum composed of 11 dentate blades, of which the posterior one is smaller than others.

Palpal femur 2.0 times longer than carapace, setal formula 11-10-5-5-7-8-3; chelal palm distinctly expanded towards internal side, chelal finger straight in dorsal view; fixed finger with 18 acute teeth; movable finger with 21 teeth, and with a tubercle between the seventh and eighth teeth from terminal (Fig. 14).

Legs (Figs. 15, 16) typical. Femur 1.7 times longer than patella, patella 3.7 times longer than deep, tarsus 1.9 times longer than tibia, setae of leg I (trochanter to tibia) 5: 11: 10: 11, setae of leg IV (trochanter to metatarsus) 2: 2: 9: 13: 14; patellae of legs III and IV each with four setae in dorsal row; femur III and IV without dorsal setae; trochanter II with five setae, trochanter III with three setae. Leg IV metatarsus and tarsus each with one basal tactile seta, tactile setae present on metatarsus $(\mathrm{TS}=0.22)$ and tarsus $(\mathrm{TS}=$ $0.24)$.

Measurements (ratios in parentheses; for the palp, the larger measurements and lower ratios only referring to male). Body length 2.50 . Carapace $0.52 \times 0.58(0.9)$. Chelicera $0.55 \times 0.25$ (2.2), movable finger length 

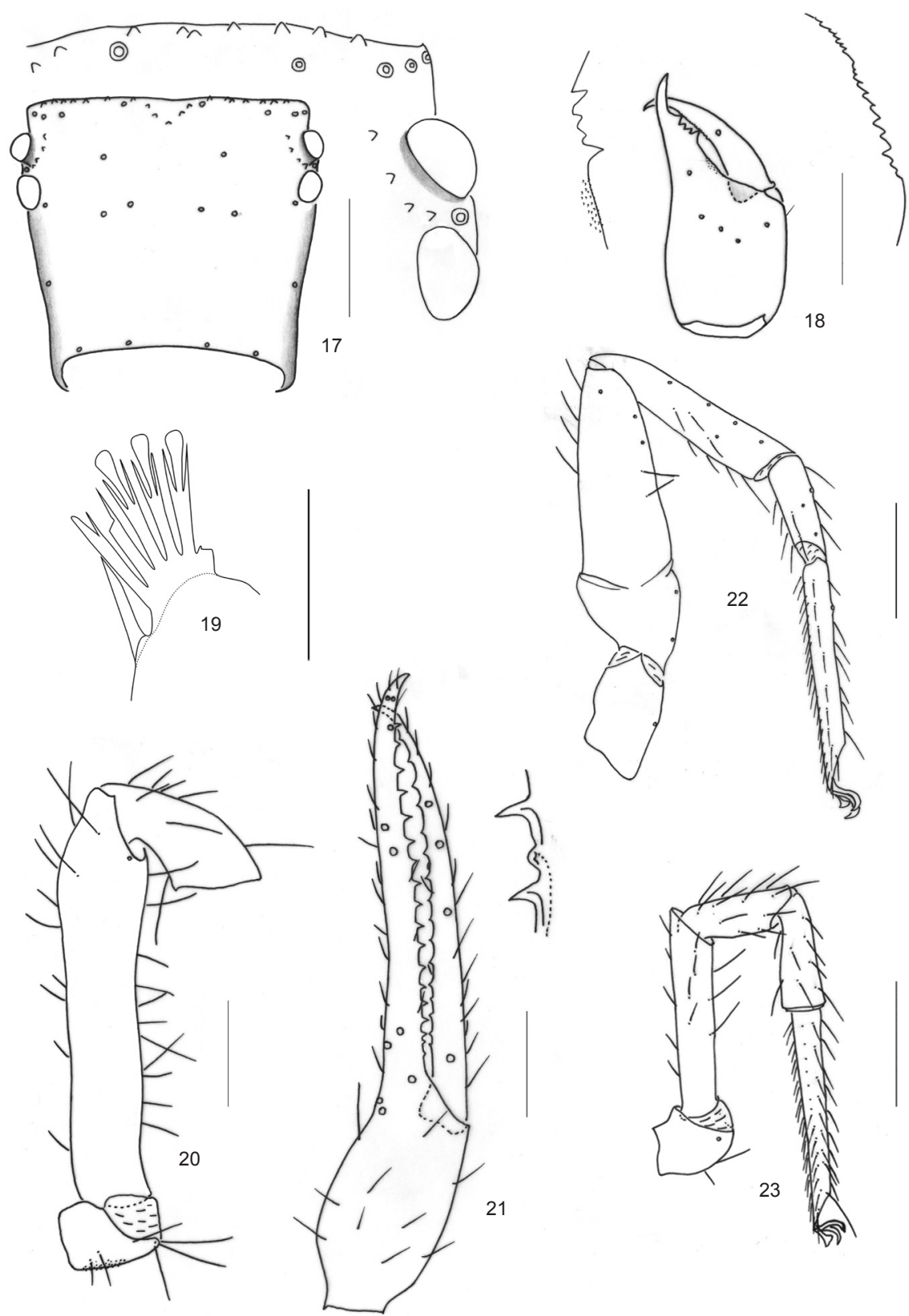

Figures 17-23. Allochthonius (Allochthonius) trigonus sp. nov. 17 - carapace, dorsal view; 18 - left chelicera, dorsal view; 19 - coxal spines; 20 - right chelal trochanter, femur and patella, ventral view; 21 right chela, lateral view; 22 - leg IV; 23 - leg I. Scale lines: $0.25 \mathrm{~mm}(22$, 23), $0.20 \mathrm{~mm}(17,18,20,21), 0.05 \mathrm{~mm}$ (19).
0.30. Palp femur 1.36-1.40×0.19-0.23 (6.1-7.2), patella $0.52-0.58 \times 0.21-0.23(2.4-2.5)$, chela 1.90 $2.03 \times 0.39-0.40$ (4.9-5.1), palm length $0.66-0.73$ (1.7-1.8), movable finger length 1.13-1.25 (1.7 $\times$ palm). Leg I femur $0.57 \times 0.08$ (7.1), patella $0.37 \times 0.08$ (4.6), tibia $0.30 \times 0.07$ (4.3), tarsus $0.58 \times 0.06(9.7)$; leg IV femur+patella $0.92 \times 0.22(4.2)$, tibia $0.65 \times 0.12$ (5.4), basitarsus $0.32 \times 0.08(4.0)$, telotarsus $0.67 \times 0.06$ (11.2).

Distribution: China (Qinghai).

\section{Allochthonius (Allochthonius) trigonus sp. nov.}

(Figs. 17-23)

Type material: Holotype male, 03.v.1978, $27^{\circ} 40^{\prime} \mathrm{N} \& 118^{\circ} 02^{\prime} \mathrm{E}$, alt. 200m, Chong' an City, Fujian Province, China, (Ps.-MHBU-FJ780503), Fusheng Huang leg.

Diagnosis: Anterior margin of carapace with 27 triangular protuberances of which eight are situated near the anterior eyes (Fig. 17); coxal spines present on coxae I and consisting of seven tridentate blades, each blade with a central branch terminally distinctly 

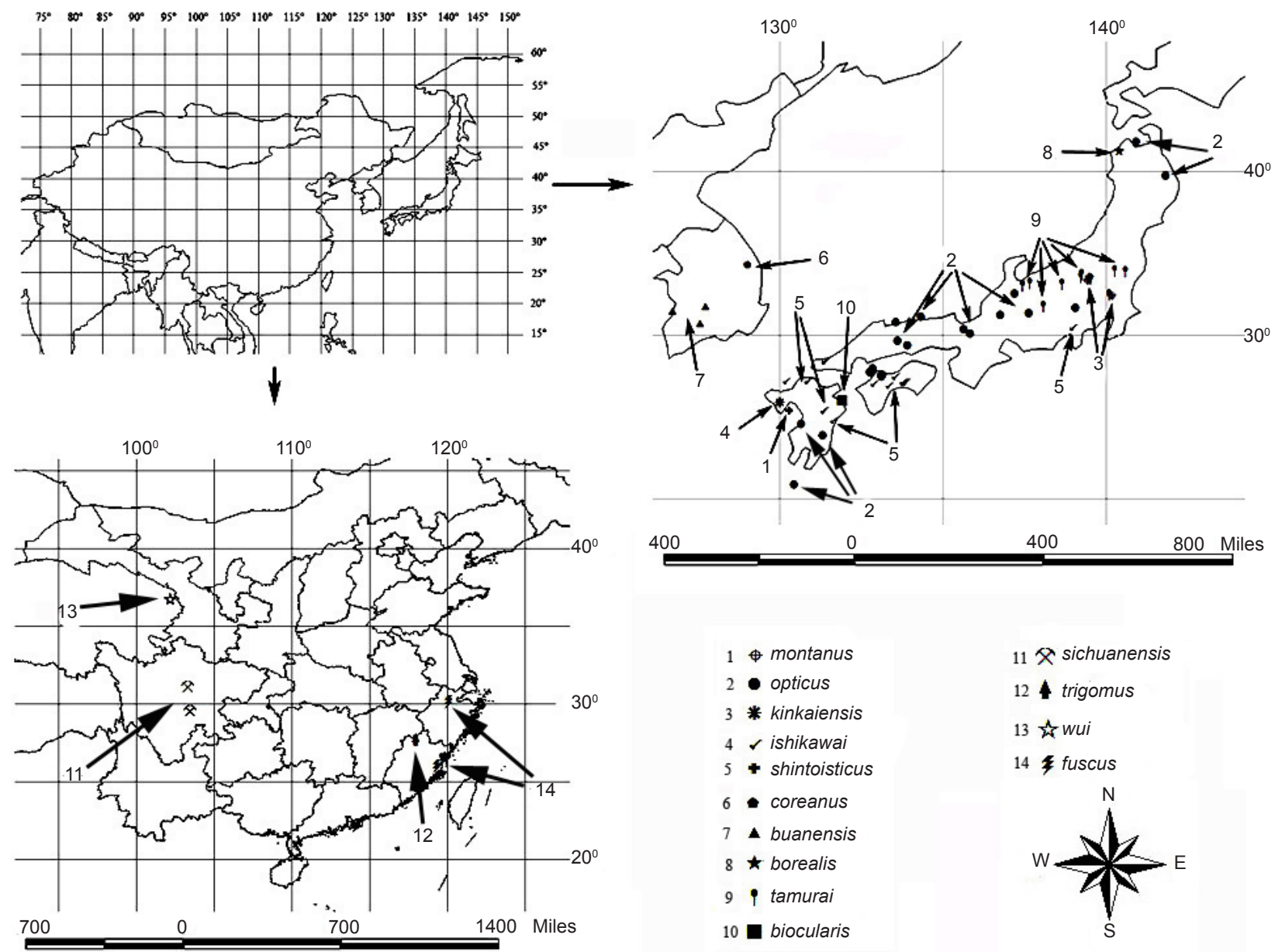

Figure 25. The known distribution of the subgenus Allochthonius (Allochthonius).

expanded as fan-shaped, six spines on a common tubercle and a single spine slightly separate (Fig. 19). This present species resembles Allochthonius (A.) borealis, but is distinguishable from the latter by the number of blades in the rallum (11 blades, in A. trigonus, and eight blades in A. borealis) and the epistome (present in latter).

Etymology: The specific name is derived from the Greek word "trigonon", means triangle, referring to the shape of triangular protuberances on the carapace anterior margin.

Description: Moderately large species. Body bright yellow. Carapace subquadrate and slightly constricted posteriorly, shorter than broad ( 0.8 times), carapace anterior margin with 27 triangular protuberances of which eight near the anterior eyes; anterior eyes with developed tapeta and situated on eye-tubercles, posterior eyes with less developed tapeta than anterior ones and without eye-tubercles; epistome absent, space between median setae straight or slightly recurved; chaetotaxy 10-4-6-2-4 (26).

Tergal chaetotaxy 4: 4: 7: 6: 8: 10:9: 12:11:8: T2T: 0. Male anterior genital operculum with eight setae, genital opening pit-like in the basal half, 13 marginal setae on each side; sternal chaetotaxy: $14+$ $2 \times 3$ suprastigmatic microsetae: $14+2 \times 3: 14+2 \times 3$ : 13: 13: 12: 12: 11: 11: 0: 2 . Coxae typical, setae P 5, I 4, II 5, III 6, IV 6; intercoxal tubercle present with two setae. Coxae I each with seven spines, of which six arranged on a common tubercle and a single spine aside.

Chelicera palm with six setae, of which a minute one located laterally; palm nearly smooth, but near the base of fixed finger with distinct granules (Fig. 18), fixed finger with one large basal and one subapical teeth, between them with two small teeth inserted; movable finger with 18 small teeth of equal length; spinneret absent. Serrula exterior with 17 lamellae, serrula interior with 14 lamellae. Rallum composed of 11 dentate blades, of which the posterior one smaller 
than others.

Palp smooth, apart from a patch of minute denticles on anterior surface of trochanter (Fig. 20). Femur 1.7 times longer than carapace, setal formula 8-11-4 4-5-2-1; chelal palm distinctly expanded towards internal side; chelal finger straight in dorsal view; chelal fixed finger with 18 teeth, of which the basal two smaller than others; movable finger with 16 teeth, with a tubercle between the sixth and seventh teeth from terminal (Fig. 21).

Legs (Figs. 22, 23) typical. Femur of leg I 1.6 times longer than patella, tarsus 2.0 times longer than tibia. Setae of leg I (trochanter to tibia) 3: 12: 11: 8, setae of leg IV (trochanter to metatarsus) 2: 2: 9: 12: 12; patellae of legs III and IV each with four setae in dorsal row; femur III and IV without dorsal setae; trochanter II with four setae, trochanter III with four setae. Leg IV with two tactile setae present on metatarsus (TS= 0.33 ) and tarsus (TS=0.23).

Measurements. (ratios in parentheses). Body length 2.0. Carapace $0.43 \times 0.51 \quad(0.8)$. Chelicera $0.48 \times 0.22(2.2)$, movable finger length 0.26 . Palp femur $0.80 \times 0.16(5.0)$, patella $0.35 \times 0.15 \quad(2.3)$, length of chela $1.22 \times 0.23$ (5.3), palm length 0.39 (1.7), movable finger length $0.82(2.1 \times$ palm $)$. Leg I femur $0.42 \times 0.08$ (5.3), patella $0.24 \times 0.08$ (3.0), tibia $0.23 \times 0.08$ (2.9), tarsus $0.43 \times 0.05$ (8.6). Leg IV femur+patella $0.68 \times 0.22(3.1)$, tibia $0.49 \times 0.10(4.9)$, metatarsus $0.23 \times 0.08(2.9)$, tarsus $0.50 \times 0.05(10.0)$.

Distribution: China (Fujian).

Remarks: Allochthonius (A.) trigonus sp. nov. is distinguished from the two previously described species Allochthonius (A.) fuscus sp. nov. and Allochthonius (A.) wui sp. nov. by the triangular protuberances present on anterior margin of carapace (absent in the other species) and the slender chela (movable finger $2.1 \times$ palm vs $1.5-1.8 \times$ palm). Allochthonius $(A$. fuscus sp. nov. shares with Allochthonius (A.) wui sp. nov. the same carapacal chaetotaxy (8-4-4-2-4 (22)), but differs from it by a slightly stouter palpal femur (5.3-5.5 times vs 6.1-7.2 times longer than broad) and chela $(1.47-1.80 \mathrm{~mm}$ vs $1.90-2.03 \mathrm{~mm})$.

\section{Allochthonius (A.) sp.}

(Figs. 24-26)

Material examined: Female, 04.vii.1990, $32^{0} 37^{\prime} \mathrm{N} \& 103^{0} 36^{\prime} \mathrm{E}$, Ngawa, Songpan County,

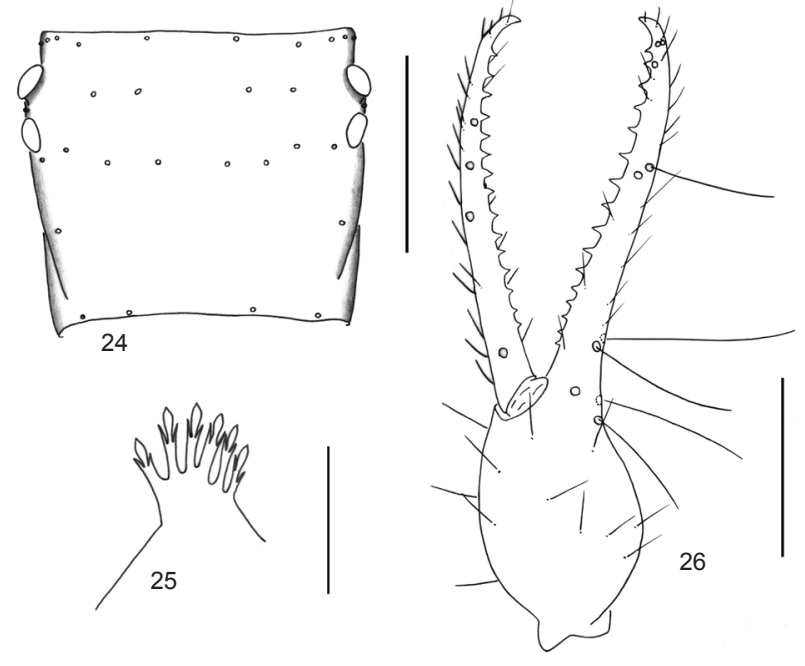

Figures 24-26. Allochthonius (Allochthonius) sp.

24 - carapace, dorsal view; 25 - coxal spines; 26 - left chela, lateral view. Scale lines: $0.25 \mathrm{~mm}(24,26), 0.05 \mathrm{~mm}(25)$.

Sichuan Province, China, (Museum ID \# Ps.-MHBUSC900704), Fusheng Huang leg.

\section{REFERENCES}

Beier, M. (1930). Alcuni Pseudoscorpioni esotici raccolti dal Prof. F. Silvestri. Bollettino del Laboratorio di Zoologia Generale e Agraria del R. Istituto Superiore Agrario in Portici 23: 197-209.

Beier, M. (1932). Pseudoscorpionidea I. Subord. Chthoniinea et Neobisiinea. Tierreich, 57: i-xx, 1-258.

Chamberlin, J.C. (1929). On some false scorpions of the suborder Heterosphyronida (Arachnida: Chelonethida). Canadian Entomologist 61: 152-155.

Chamberlin, J.C. (1931). The arachnid order Chelonethida. Stanford University Publications, University Series (Biol. Sci.), 7: 1-284.

Ellingsen, E. (1907). On some pseudoscorpions from Japan collected by Hans Sauter. Nytt Magasin for Naturvidenskapene 45: 1-17.

Harvey, M.S. (1991). Catalogue of the Pseudoscorpionida. Manchester University Press, Manchester, 1-726pp.

Harvey, M.S. (1992). The phylogeny and classification of the Pseudoscorpionida (Chelicerata: Arachnida). Invertebrate Taxonony 6: 1373-1435.

Harvey, M.S. (2009). Pseudoscorpions of the World, version 1.2., Western Australian Museum, Available from: http:// www.museum.wa.gov.au/arachnids/pseudoscorpions/ (accessed 7 January 2011).

Judson, M.L.I. (2007). A new and endangered species of the pseudoscorpion genus Lagynochthonius from a cave in Vietnam, with notes on chelal morphology and the composition of the Tyrannochthoniini (Arachnida, 


\section{Key to species of the subgenera Allochthonius (Allochthonius)}

1. Cheliceral palm with five setae on dorsal surface, one seta on ventral surface....Allochthonius (A.) buanensis Cheliceral palm with five or six setae on dorsal surface, without any seta on ventral surface ........................2

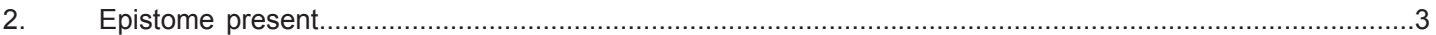

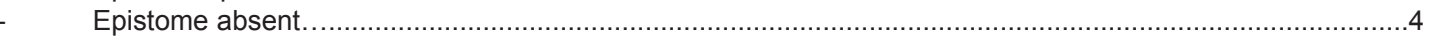

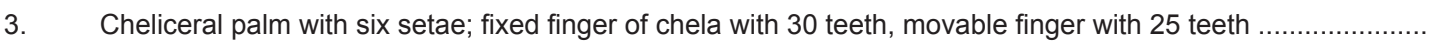
.......................................................................................................... Allochthonius (A.) coreanus Cheliceral palm with five setae; fixed finger of chela with 18 to 20 teeth, movable finger with eight to nine acute spaced teeth on the apical half and nine to ten reduced or vestigial teeth on the basal half .....

\section{Allochthonius (A.) borealis}

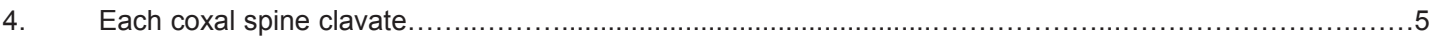

- $\quad$ Each coxal spine with tridentate branches and the central one terminally spatulate (Fig. 27) or expanded as

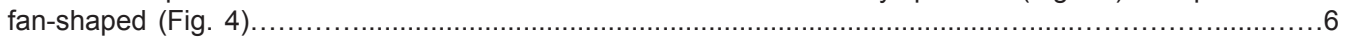

5. Fixed finger of chelicera with a very large posterior tooth, the others smaller and of equal length................ Fixed finger of chelicera with a large anterior and nearly equal posterior tooth, with two or three smaller intervening ones ..............................................................................Allochthonius (A.) shintoisticus

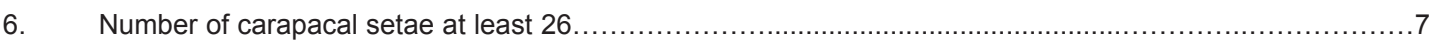

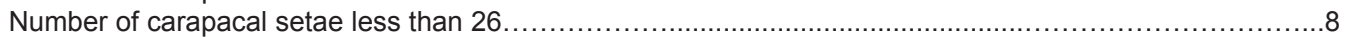

7. Anterior margin of carapace with protuberances..............................lochthonius (A.) trigonus sp. nov. Anterior margin of carapace without protuberances..............................Allochthonius (A.) sichuanensis

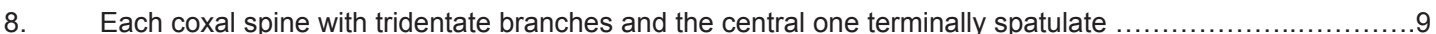

- $\quad$ Each coxal spine with tridentate branches and the central one terminally expanded as fan-shaped.............10

9. Carapacal chaetotaxy 8 (or 9 or 10)-4-4-2-4, 22 (or 23 or 24); fixed finger of chelicerae with four or five (rarely three) conspicuous marginal teeth, movable finger with about 12 to 16 fine denticulations. Allochthonius (A.) tamurai

- $\quad$ Carapacal chaetotaxy 6-4-2-2-4, 18; fixed finger of chelicerae with one large and seven or nine middle or small marginal teeth, movable finger with 16 to 20 fine denticulations.............Allochthonius (A.) montanus

10. Color of chelal palm distinctly darker than other segments (Fig. 25) ..............Allochthonius (A.) fuscus sp. nov.

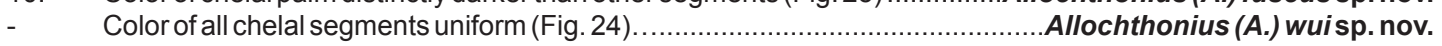

Chelonethi, Chthoniidae). Zootaxa 1627: 53-68.

Lee, W.K. (1982). Pseudoscorpions (Arachnida) from Korea II. A new species of the genus Allochthonius. Basic Science Review, Chonbuk National University, Korea 5: 75-80.

Morikawa, K. (1954). On some pseudoscorpions in Japanese lime-grottoes. Memoirs of Ehime University (2B) 2: 79 87.

Morikawa, K. (1956). Cave pseudoscorpions of Japan (I). Memoirs of Ehime University (2B) 2: 271-282.

Morikawa, K. (1960). Systematic studies of Japanese pseudoscorpions. Memoirs of Ehime University (2B) 4: $85-172$.

Morikawa, K. (1970). Results of the speleological survey in South Korea 1966. XX. New pseudoscorpions from South Korea. Bulletin of the National Science Museum of Tokyo 13: $141-148$.

Muchmore, W.B. (1967). Pseudotyrannochthoniine pseudoscorpions from the western United States. Transactions of the American Microscopical Society 86: 132-139.

Sakayori, H. (1999). A new species of the genus Allochthonius (Pseudoscorpion, Chthoniidae) from Mt. Tsukuba, central Japan. Edaphologia 63: 81-85.

Sakayori, H. (2000). A new species of the genus Allochthonius (Pseudoscorpion, Chthoniidae) from Mt. Kohshin, Tochigi Prefecture, Central Japan. Edaphologia 65: 13-18.
Sakayori, H. (2003). External morphology of nymphal stages of Allochthonius tamurai Sakayori, 1999 (Pseudoscorpionida: Chthoniidae). Bulletin of Ibaraki Nature Museum 6: 23 31 .

Sato, H. (1984). Allochthonius borealis, a new pseudoscorpion (Chthoniidae) from Tohoku District, Japan. Bulletin of the Biogeographical Society of Japan 39: 17-20.

Schawaller, W. (1995). Review of the pseudoscorpion fauna of China (Arachnida: Pseudoscorpionida). Revue Suisse de Zoologie 102: 1045-1064.

Vachon,M.(1941). ChthoniustetrachelatusP.(Pseudoscorpions) et ses formes immatures (1re note). Bulletin du Muséum national d'Histoire naturelle, Paris (2)13: 442-449.

Author details: JUNFANG $\mathrm{Hu}$ is a master student in Hebei University, Hebei Province, China. Her major is zoology, mainly to classify the pseudoscorpions on fauna of China, and her supervisor is Prof. Feng Zhang.

PROF. FEng ZhANG is currently teaching students, undertaking and supervising research activities in Hebei University. His recent research focus is on systematics of Arachnida. He has published more than 90 research papers in leading national and international journals. He has produced 12 master students in field of Arachnida. 